\title{
Structure Optimal Design of Electromagnetic Levitation Load Reduction Device for Hydroturbine Generator Set
}

\author{
Qingyan Wang, ${ }^{1,2}$ Hongzhong Ma, ${ }^{1,2}$ Shengrang Cao, ${ }^{1,2}$ and Bingyan Chen ${ }^{1,3,4}$ \\ ${ }^{1}$ College of Energy and Electrical Engineering, Hohai University, Nanjing, China \\ ${ }^{2}$ Research Center for Renewable Energy Generation Engineering, Ministry of Education, Beijing, China \\ ${ }^{3}$ Hohai University Nantong Institute of Marine and Offshore Engineering, Nantong, China \\ ${ }^{4}$ Jiangsu Province Key Laboratory of Environmental Engineering, Nanjing, China
}

Correspondence should be addressed to Qingyan Wang; wqy6990@foxmail.com

Received 8 October 2014; Revised 8 February 2015; Accepted 20 February 2015

Academic Editor: Gerhard-Wilhelm Weber

Copyright (C) 2015 Qingyan Wang et al. This is an open access article distributed under the Creative Commons Attribution License, which permits unrestricted use, distribution, and reproduction in any medium, provided the original work is properly cited.

\begin{abstract}
Thrust bearing is one part with the highest failure rate in hydroturbine generator set, which is primarily due to heavy axial load. Such heavy load often makes oil film destruction, bearing friction, and even burning. It is necessary to study the load and the reduction method. The dynamic thrust is an important factor to influence the axial load and reduction design of electromagnetic device. Therefore, in the paper, combined with the structure features of vertical turbine, the hydraulic thrust is analyzed accurately. Then, take the turbine model HL-220-LT-550, for instance; the electromagnetic levitation load reduction device is designed, and its mathematical model is built, whose purpose is to minimize excitation loss and total quality under the constraints of installation space, connection layout, and heat dissipation. Particle swarm optimization (PSO) is employed to search for the optimum solution; finally, the result is verified by finite element method (FEM), which demonstrates that the optimized structure is more effective.
\end{abstract}

\section{Introduction}

For vertical shaft hydroturbine generator set, the axial load is mainly composed of two parts, total gravity of rotating parts and hydraulic axial thrust. In large and medium hydropower units, it could be up to thousands of tons. With the development of unit capacity, axial load shows the growing tendency, and some in actual operations have exceeded rated loads, which would lead to serious deformations of thrust tiles, oil film breakdown, and mechanical strength aging. In particular, under long-term loading conditions, oil film breakdown would cause in future mechanical abrasion and heat problems [1-3]; thrust bearing has been regarded as one of the most complex components in hydropower plant [3-5]. In recent years, bearing faults happen all the time, such as in Gezhouba, Baishan, and Wujiangdu, whose characteristics mainly show high temperature in certain areas of pads or burning-out. Reference [2] indicated that the bearing failure rate takes up almost $60 \%$ of the total mechanical faults in the whole unit. With the increasing proportion of hydropower in power system, the reliability and stability of unit operation become much more pressing concerns to deal with. How to develop new technical methods to reduce axial load and enhance reliability have become a key technology in the design of hydropower generator unit and capacity-increasing transformation.

Ma et al. proposed a new method by using permanent magnetic and electromagnetic levitation devices to reduce the axial load [2-4]. In electromagnetic part, the main idea is to use the electromagnetic towing force to counteract most of the downward axial load, about $80 \%$; in this way, thrust bearing just needs to bear about $20 \%$ of the total load, the frictional loss of oil films could be declined, and failure rate is accordingly reduced. References $[3,4]$ have analyzed the structure, feasibility, and predomination when compared with traditional supporting forms. However, hydraulic axial thrust has a big impact on axial load and reduction design; it is necessary to be analyzed accurately. Besides, the structure parameters of the device are interactional, which determine 


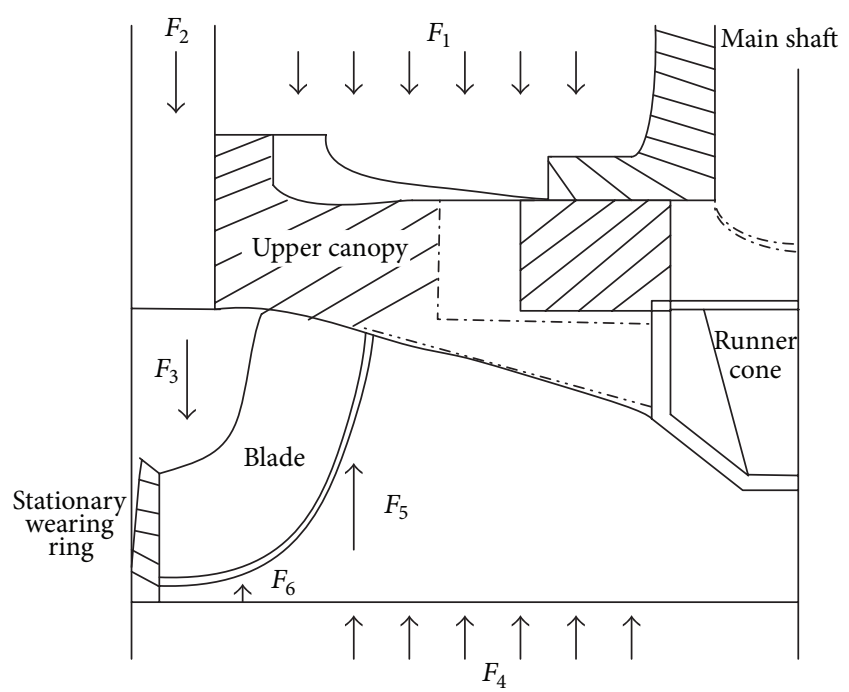

FIGURE 1: Structure of turbine runner.

the performance of the device. Therefore, to improve the efficiency, combined with the thrust analysis and original structure, a mathematical model of electromagnetic device is established and PSO is employed to search for the optimum relation.

\section{Hydraulic Axial Thrust of Turbine}

According to stress and structure analysis of the runner (shown in Figure 1), the hydraulic thrust is composed of water pressure on upper canopy, runner band, ingress, exit, the inner surface of the cavity flow path, and the buoyancy of runner $[6,7]$. If there is no outlet entrance on the surface of upper canopy, the force $F_{1}$ on the upper canopy is associated with static pressure of upper wearing ring ingress, which can be described as follows:

$$
\begin{gathered}
F_{1}=\gamma \pi\left[\frac{2 H_{1} g-\left(K_{0} \pi n R_{1} / 30\right)^{2}}{2 g}\left(R_{1}^{2}-R_{0}^{2}\right)\right. \\
\left.+\left(\frac{K_{0} \pi n}{30}\right)^{2}\left(\frac{R_{1}^{4}-R_{0}^{4}}{4 g}\right)\right],
\end{gathered}
$$

where $\gamma$ is the unit weight of water $\left(\mathrm{N} / \mathrm{m}^{3}\right) ; g$ is acceleration of gravity $\left(\mathrm{N} / \mathrm{s}^{2}\right) ; K_{0}$ is angular velocity coefficient of water on upper canopy; generally, $K_{0}=0.5$ [6]; $R_{1}$ is radius of upper wearing ring ingress $(\mathrm{m}) ; H_{1}$ is static head of ingress of upper wearing ring $(\mathrm{m})$ [7], whose specific expression is

$$
H_{1}=H_{0}-\frac{1}{4 \pi g R_{1}} \sqrt{\frac{Q^{2}}{b^{2}}+\frac{3600 \eta_{t}^{2} g^{2} H^{2}}{n_{r}^{2}}},
$$

where $H_{0}$ is rated head $(\mathrm{m}) ; \mathrm{Q}$ is hydraulic turbine discharge $\left(\mathrm{m}^{3} / \mathrm{s}\right) ; b$ is turbine blade height $(\mathrm{m}) ; \eta_{t}$ is the efficiency of hydraulic turbine; $H$ is working head $(\mathrm{m}) ; n_{r}$ is turbine rated speed.

The force $F_{2}$ on runner band depends on the static head of the lower wearing ring ingress $H_{2}(\mathrm{~m})$, the diameter of
TABLE 1: Hydraulic thrust of turbine.

\begin{tabular}{lc}
\hline Parameter & Data \\
\hline Rated output $N(\mathrm{MW})$ & 204.1 \\
Rated flow $Q\left(\mathrm{~m}^{3} / \mathrm{s}\right)$ & 304 \\
Rated head $H(\mathrm{~m})$ & 76.2 \\
Rated speed $n_{r}(\mathrm{r} / \mathrm{min})$ & 107 \\
Draft height $H_{s}(\mathrm{~m})$ & -4.5 \\
Gravity of rotating parts $G(\mathrm{kN})$ & 8722 \\
Force component $F_{1}(\mathrm{kN})$ & 6337 \\
Force component $F_{2}(\mathrm{kN})$ & 1982 \\
Force component $F_{3}(\mathrm{kN})$ & 18.2 \\
Force component $F_{4}(\mathrm{kN})$ & -548 \\
Force component $F_{5}(\mathrm{kN})$ & 3436 \\
Force component $F_{6}(\mathrm{kN})$ & 13 \\
\hline
\end{tabular}

upper wearing ring ingress $D_{1}(\mathrm{~m})$, and the diameter of lower wearing ring ingress $D_{2}(\mathrm{~m})$, and it is often expressed as

$$
F_{2}=\frac{\gamma \pi\left(H_{1}+H_{2}\right)\left(D_{2}^{2}-D_{1}^{2}\right)}{8} .
$$

On turbine blade inlet, the force $F_{3}$ is given in (4), where $V_{1 r}=Q /\left(\pi D_{1} b\right)$ is the axial component of the absolute speed on the upper wearing ring ingress [7] and $\varphi$ is the inclination angle between runner inlet section and main shaft:

$$
F_{3}=\frac{\gamma Q V_{1 r} \sin \varphi}{g} .
$$

On blade outlet, the force $F_{4}$ is in connection with draft height $H_{s}$ and exit velocity $V_{2}$ :

$$
F_{4}=\gamma\left(H_{s}-\frac{V_{2}^{2}}{2 g}\right)\left(\frac{\pi D_{2}^{2}}{4}\right) .
$$

According to the flow momentum theorem on runner inlet and outlet, the force $F_{5}$ on runner cavity and the upward buoyant force on the runner submerged in the water $F_{6}$ can be described as follows:

$$
\begin{gathered}
F_{5}=\frac{\gamma Q V_{2}}{g}, \\
F_{6}=\gamma \frac{G_{r}}{\gamma_{t}},
\end{gathered}
$$

where $G_{r}$ is the runner weight $(\mathrm{kg})$ and $\gamma_{t}$ is the specific gravity of runner. Combined with structure parameters of the turbine model HL-220-LT-550 in Ankang hydropower station, each force component is calculated and shown in Table 1.

The hydraulic thrust under the rated condition is $F_{\text {th }}=$ $F_{1}+F_{2}+F_{3}-F_{4}-F_{5}-F_{6}=5436 \mathrm{kN}$, and the total axial load is $F_{T}=G+F_{\text {th }}=14158 \mathrm{kN}$, about 1387 tons. It can be seen that the hydraulic thrust is up to $62 \%$ of the gravity of rotating parts and up to $39 \%$ of the total axial load. So, the hydraulic thrust, as one important component of the axial load, should not be ignored. The thrust force varies with water head, speed, and flow, whose value on other work conditions could be evaluated according to (1)-(6). 


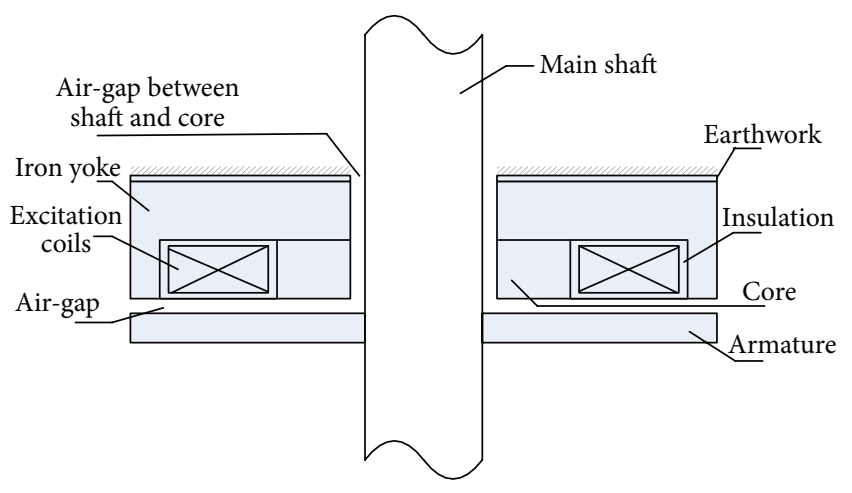

Figure 2: Structure of hybrid magnetic electromagnetic device.

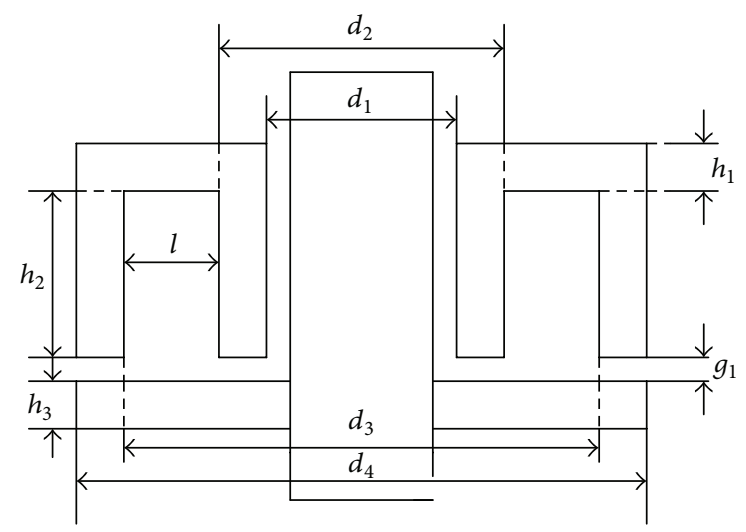

FIGURE 3: The profile diagram of electromagnetic device.

\section{Modeling of Electromagnetic Levitation Device}

3.1. Principle of Electromagnetic Levitation Device. The load shedding device (i.e., DC sucker electromagnetic levitation device) has the character of compact conformation [3]. The device could be installed outer flank of main shaft, which consists of the rotating armature iron (connected with the main shaft) and fixed iron core (fixed by the earthwork), as shown in Figure 2. The excitation coils are placed in soft magnetic materials (fixed iron core) and contained in epoxy, which can keep good insulation and is suitable for high humidity environment.

When the device is electrified, armature would be attracted, and there exists an upward pull. Due to the connection of armature and main shaft, the upward attractive force is passed to main shaft, the rotating parts of hydrogenerator set could be subject to the pulling force, and the force can be adjusted according to the actual operation. The profile diagram for the electromagnetic levitation device is shown in Figure 3.

Assumed to neglect the effect of saturation and flux leakage, the electromagnetic force generated by electromagnetic device can be expressed as follows [8, 9]:

$$
F_{\text {ele }}=\frac{1}{2 \mu_{0} \pi}\left(\frac{N I}{R_{m}}\right)^{2}\left(\frac{4}{\left(d_{2}^{2}-d_{1}^{2}\right)}+\frac{4}{2 \mu_{0} \pi\left(d_{4}^{2}-d_{3}^{2}\right)}\right) .
$$

$R_{m}$ is magnetic reluctance and can be expressed as

$$
\begin{aligned}
R_{m}= & \frac{g}{\mu_{0}}\left(\frac{1}{S_{1}}+\frac{1}{S_{2}}\right)+\frac{h_{2}+h_{1} / 2+h_{3} / 2}{\mu}\left(\frac{1}{S_{1}}+\frac{1}{S_{2}}\right) \\
& +\frac{1}{2 \pi \mu}\left(\frac{1}{h_{1}}+\frac{1}{h_{3}}\right) \ln \frac{d_{34}}{d_{12}},
\end{aligned}
$$

where $d_{12}=\left(d_{1}+d_{2}\right) / 4$ and $d_{34}=\left(d_{3}+d_{4}\right) / 4 ; \mu$ is the magnetic permeability of iron.

3.2. Mathematical Model. Electromagnetic levitation device uses ring configuration; in order to improve the utilization ratio of iron cores, the areas of inner and outer rings should be identical. Magnetic pressure and system loss are determined by coil turns and exciting current; therefore, assume that the design variable is $X=\left[d_{2}, l, h_{2}, N, I\right]$. In this paper, take excitation loss and total weight of electromagnet as the objective functions:

$$
\begin{gathered}
P_{\text {loss }}=\pi I^{2} N \rho d_{23}, \\
M=\rho_{\mathrm{Fe}} \frac{\pi}{4}\left[\left(d_{4}^{2} h_{2}-d_{3}^{2} h_{2}\right)+\left(d_{2}^{2} h_{2}-d_{1}^{2} h_{2}\right)\right. \\
\left.+\left(d_{4}^{2}-d_{1}^{2}\right)\left(h_{3}+h_{1}\right)\right],
\end{gathered}
$$

where $\rho_{\mathrm{Fe}}$ is the density of ferrite. According to the design requirement, electromagnetic force should not be less than $F_{\text {min }}=0.7 F_{T}$, while electromagnetic force should not be larger than $F_{\max }=0.8 F_{T}$; otherwise, it would cause the instability of the hydrogenerator unit, so

$$
0.7 F_{T}<F_{\text {ele }}<0.8 F_{T} \text {. }
$$

Structure design should consider restraining factors, such as the actual installation space, cabling requirement, and heat dissipation. To guarantee that the outer and inner magnetic flux intensities are more or less the same, outer and inner ring areas might be equal. So, there exist the following constraints:

$$
\begin{gathered}
S_{1}-S_{2}=0, \\
0.08<h_{2}<0.25, \\
3000<N<8000, \\
h_{2} l \geq \frac{\pi d_{w}^{2} K_{y} N}{\left(4 K_{t}\right)},
\end{gathered}
$$

where $d_{w}$ is the wire diameter; $k_{y}$ is the margin coefficient, generally set as $1.2 ; k_{t}$ is filling factor of the coil and is about 0.5 . The wire of electromagnetic device is concerned with the allowed maximum current. In this paper, choose the nominal wire diameter of $1.784 \mathrm{~mm}$. According to the above, the limit condition is given as

$$
0<I<8.0 .
$$

\section{Optimization Technology and Experiment}

The essence of PSO is that letting information about good solutions spread around the population, each particle would 
TABLE 2: Comparison of results before and after optimization.

\begin{tabular}{lcc}
\hline Parameters & $\begin{array}{c}\text { Before } \\
\text { optimization }\end{array}$ & $\begin{array}{c}\text { After } \\
\text { optimization }\end{array}$ \\
\hline$d_{2}(\mathrm{~m})$ & 3.464 & 3.667 \\
$d_{3}(\mathrm{~m})$ & 4.664 & 4.563 \\
$h_{2}(\mathrm{~m})$ & 0.12 & 0.100 \\
$N$ & 5000 & 4163 \\
$I(\mathrm{~A})$ & 3 & 3.2614 \\
$F_{\text {ele }}(\mathrm{kN})$ & 1132.64 & 1094.723 \\
$M($ ton $)$ & 109.254 & 108.685 \\
$P_{\text {loss }}(\mathrm{kW})$ & 4.307 & 4.291 \\
\hline
\end{tabular}

tend to move to good areas $[10,11]$. At each iteration time $t$, particle $i$ is moved to a new position by adding a velocity term $\mathbf{V}_{i}(t+1)$ to its current position $\mathbf{X}_{i}(t+1)$ according to

$$
\begin{gathered}
\mathbf{V}_{i}(t+1)=\omega \mathbf{V}_{i}(t)+c_{1} r_{1}\left[X_{P \text { best }, i}-X_{i}(t)\right] \\
+c_{2} r_{2}\left[X_{\text {Gbest }}-X_{i}(t)\right] \\
\mathbf{X}_{i}(t+1)=\mathbf{X}_{i}(t)+\mathbf{V}_{i}(t+1),
\end{gathered}
$$

where $i=1,2, \ldots$, pop and pop is the population size; $X_{P \text { best }, i}$ is the best position of particle $i$; $X_{\text {Gbest }}$ is the global best position; $\omega$ is called inertia weight; $c_{1}$ and $c_{2}$ are acceleration factors; $r_{1}$ and $r_{2}$ are random selection of constants among $[0,1]$. Optimization design $((7)$ to $(12))$ is a constrained nonlinear problem; by the constructed penalty functions, the problem can be simplified as follows:

$$
\begin{aligned}
f_{\text {itness }}= & \lambda_{1} P_{\text {loss }}+\lambda_{2} V+L_{1}+L_{2} \\
\text { s.t. } & d_{1}<d_{2} \\
& 0<l \leq 0.6 \\
& 0<I<8.0 \\
& 3000<N<8000 \\
& 0.08<h_{2}<0.25
\end{aligned}
$$

where $\lambda_{1}, \lambda_{2}$ are weight coefficients and $\lambda_{1}+\lambda_{2}=1 ; L_{1}, L_{2}$ are the penalty functions, whose specific descriptions are shown as

$$
\begin{aligned}
& L_{1}= \begin{cases}0, & \text { if } \operatorname{sign}\left(h_{2} l-\frac{\pi d_{w}^{2} K_{y} N}{4 K_{t}}\right) \geq 0 \\
10^{5}\left|h_{2} l-\frac{\pi d_{w}^{2} K_{y} N}{4 K_{t}}\right| & \text { else, }\end{cases} \\
& L_{2}=10^{5}\left|S_{1}-S_{2}\right| .
\end{aligned}
$$

In this paper, assume that $g=0.005 \mathrm{~m}, h_{1}=h_{3}=0.3 \mathrm{~m}$, $d_{1}=2 \mathrm{~m}$, and $d_{4}=5.5 \mathrm{~m}$. The algorithm parameters are set

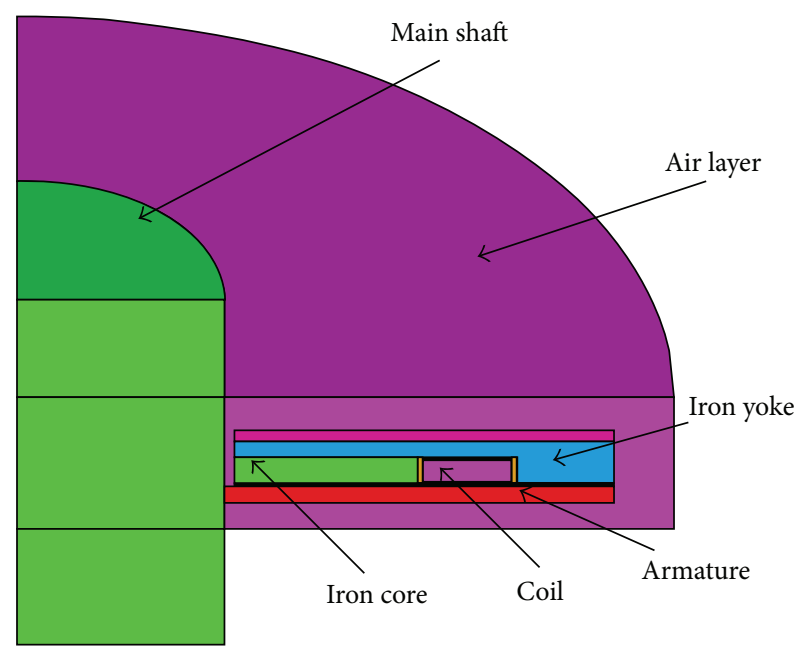

FIGURE 4: 3D finite element model of electromagnetic device.

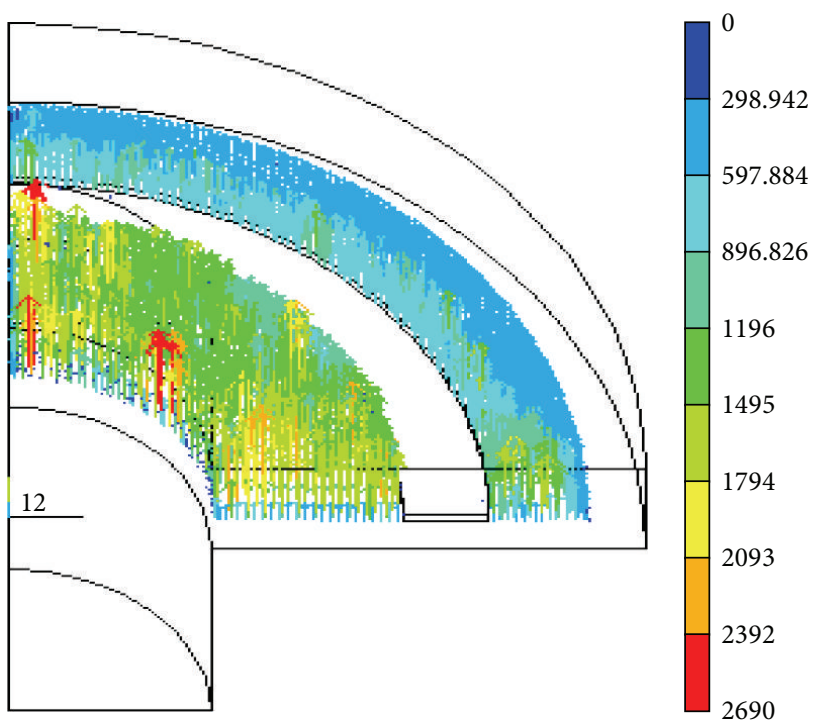

FIGURE 5: Vector distribution of electromagnetic force.

as follows: $\lambda_{1}=\lambda_{2}=0.5, t_{\max }=200$, pop $=36, \omega=0.8$, and $c_{1}=c_{2}=0.8$. Test for 50 times; select the best result, shown in Table 2.

To verify the result, use ANSYS software [12] to simulate $1 / 4$ of this device (shown in Figure 4). The simulation result is $F_{\text {ele }}^{\prime}=1053.46 \mathrm{kN}$, the error between FEM and numerical analysis is less than 5\%, and the electromagnetic force distribution on the armature is shown in Figure 5.

From Table 2, the electromagnetic forces between preand postoptimization have little difference, not exceeding $4 \%$, but the required magnetic potential is decreased about 1423 ampere turns, saving about $10.5 \%$. When guaranteeing the load reduction requirement, the system loss and total gravity are decreased by PSO. The reason is that, after optimization technology, the effective pole areas grow from $12.949 \mathrm{~m}^{2}$ to $14.818 \mathrm{~m}^{2}$. When the air-gap keeps in step, there are two ways to increase electromagnetic force, by raising 
the magnetic pressure or effective pole areas. The magnetic flux density is limited by material properties, and raising magnetic pressure would be susceptible to magnetic saturation problem. Meanwhile, there might be increase in the system loss. Therefore, on the condition of actual allowed space, increasing effective pole areas by optimization technology would meet the design task and simultaneously reduce the excitation loss and manufacturing cost.

\section{Conclusion}

The analytic process about hydraulic thrust has been described in this paper, whose calculation is a critical factor to the axial load and reduction design of the hydroturbine generator set. According to the calculation of turbine model HL220-LT-550, the design requirement, and structure restriction of electromagnetic levitation load reduction device, the mathematical model is built. Then, use PSO to search for the optimum solution, and, by comparison, the optimization solution makes the electromagnetic device more efficient and of more performance. The analysis of hydraulic thrust can be applied to other similar turbines; the structural optimization method also could be extended to similar electromagnetic devices.

\section{Conflict of Interests}

The authors declare that there is no conflict of interests regarding the publication of this paper.

\section{Acknowledgments}

This work was supported by the National Natural Science Foundation of China (Grant no. 51177039), Doctoral Fund of Ministry of Education of China (Grant no. 20090094110011), the Nantong Science and Technology Project, Nantong, China (Grant no. BK2014024), and the Open Project of Jiangsu Province Key Laboratory of Environmental Engineering, Nanjing, China (Grant no. KF2014001). Meanwhile, the authors would like to thank Professor Ping Ju for his valuable discussions in electromagnetic device modeling.

\section{References}

[1] J. Ferguson, "GE hydro thrust bearings-applying development work to upgrading existing bearings," in Proceedings of the IEEE International Electric Machines and Drives Conference (IEMDC '99), pp. 809-811, May 1999.

[2] H. Z. Ma, Q. Y. Wang, and P. Ju, "Study of the load reduction for hydro-generator bearing by hybrid magnetic levitation," International Journal of Applied Electromagnetics and Mechanics, vol. 43, no. 3, pp. 215-226, 2013.

[3] H. Z. Ma, B. Wang, and P. Ju, "Feasibility of mixed magneticlevitation weight support system of hydroelectric generating set," Journal of Hohai University: Natural Sciences, vol. 38, no. 4, pp. 467-471, 2010.

[4] H. Ma, Z. Geng, Q. Wang, and Z. Zhang, "Analysis and calculation for heating and temperature rise of magnetic levitation device," Proceedings of the Chinese Society of Electrical Engineering, vol. 32, no. 30, pp. 126-132, 2012.
[5] Z. P. Xia, Z. Q. Zhu, and D. Howe, "Analytical magnetic field analysis of halbach magnetized permanent-magnet machines," IEEE Transactions on Magnetics, vol. 40, no. 4 I, pp. 1864-1872, 2004.

[6] D. Y. Liu, G. H. You, F. Wang, and J. Zhang, "Calculation and analysis of axial thrust acting on turning wheel of flow-mixing reversible hydraulic turbines," Journal of Hohai University: Natural Sciences, vol. 5, 2004.

[7] R. F. Li, X. P. Li, X. Qian, T. Xu, Y. Wang, and Y. Zeng, "Calculation of axial water thrust of the inverted-installation runner of mixed-flow turbine," Journal of Waterpower, vol. 5, pp. 50-52, 2001.

[8] N. R. Nannapaneni, Fundamentals of Engineering Electromagnetics, Mechanical Industry Press, Beijing, China, 2006.

[9] E. Atienza, M. Perrault, F. Wurtz, V. Mazauric, and J. Bigeon, "Methodology for the sizing and the optimization of an electromagnetic release," IEEE Transactions on Magnetics, vol. 36, no. 4 I, pp. 1659-1663, 2000.

[10] M. Kaucic, "A multi-start opposition-based particle swarm optimization algorithm with adaptive velocity for bound constrained global optimization," Journal of Global Optimization, vol. 55, no. 1, pp. 165-188, 2013.

[11] P. Umapathy, C. Venkataseshaiah, and M. S. Arumugam, "Particle swarm optimization with various inertia weight variants for optimal power flow solution," Discrete Dynamics in Nature and Society, vol. 2010, Article ID 462145, 15 pages, 2010.

[12] J.-A. Duan, H.-B. Zhou, and N.-P. Guo, "Electromagnetic design of a novel linear maglev transportation platform with finiteelement analysis," IEEE Transactions on Magnetics, vol. 47, no. 1, pp. 260-263, 2011. 


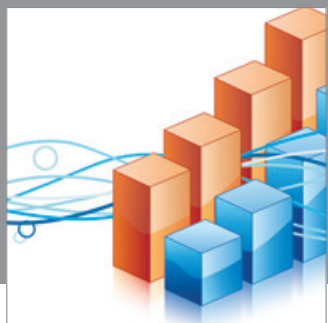

Advances in

Operations Research

mansans

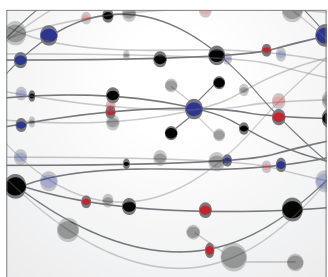

The Scientific World Journal
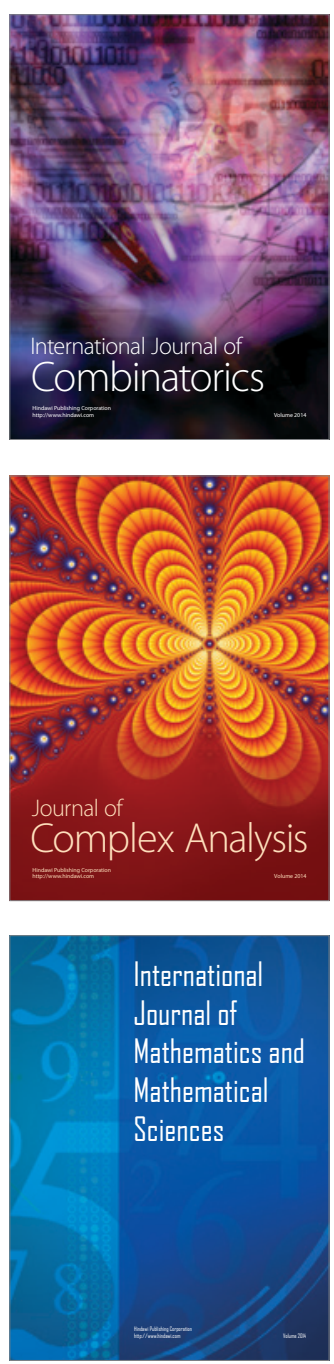
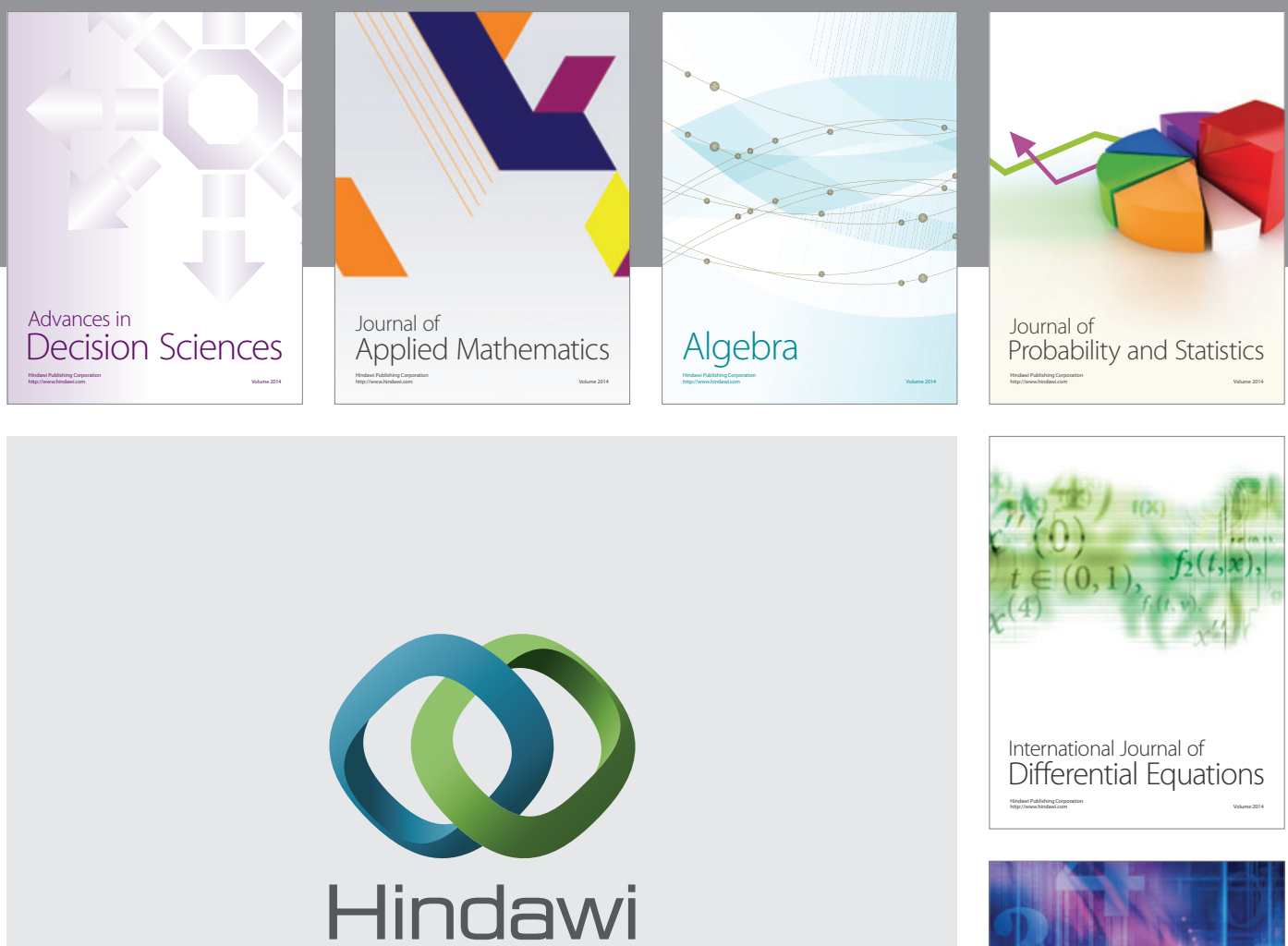

Submit your manuscripts at http://www.hindawi.com
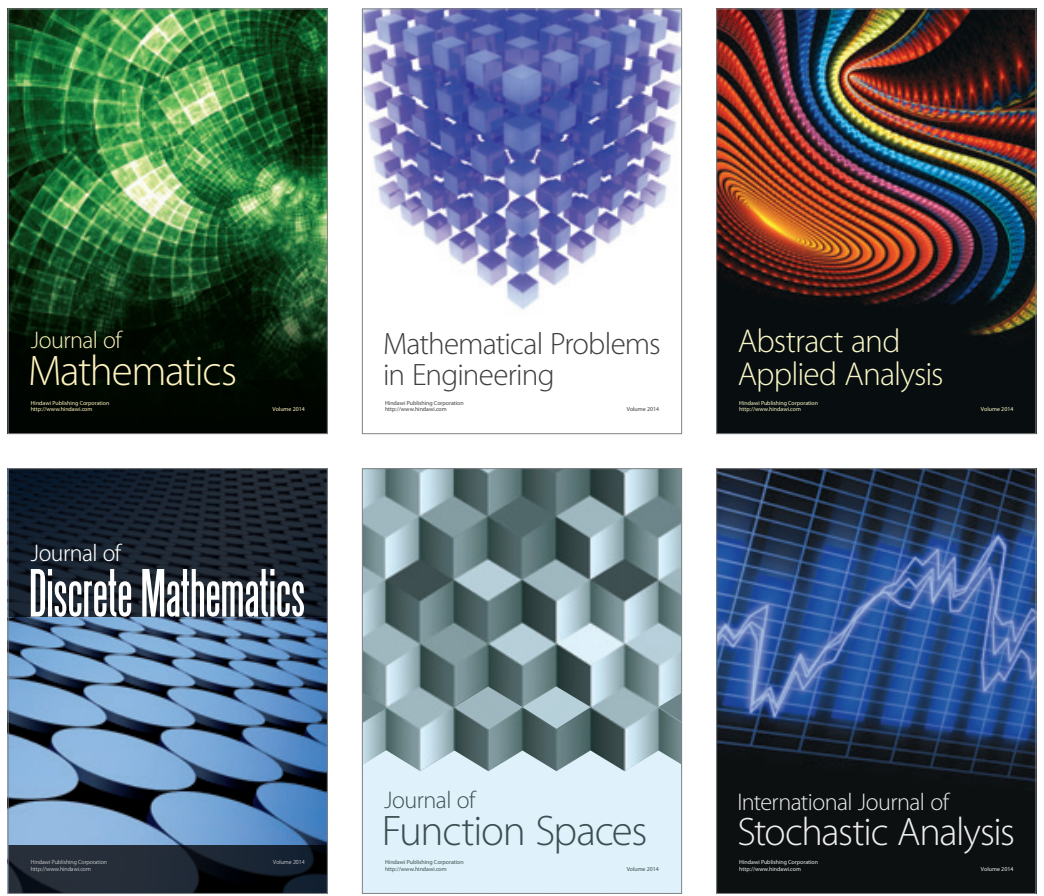

Journal of

Function Spaces

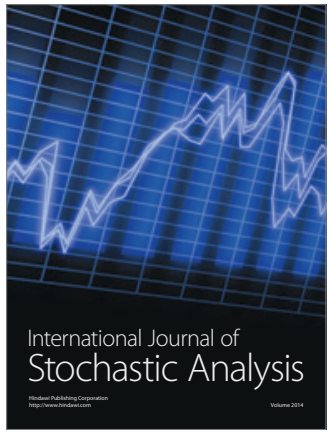

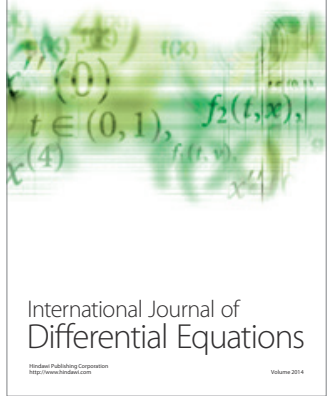
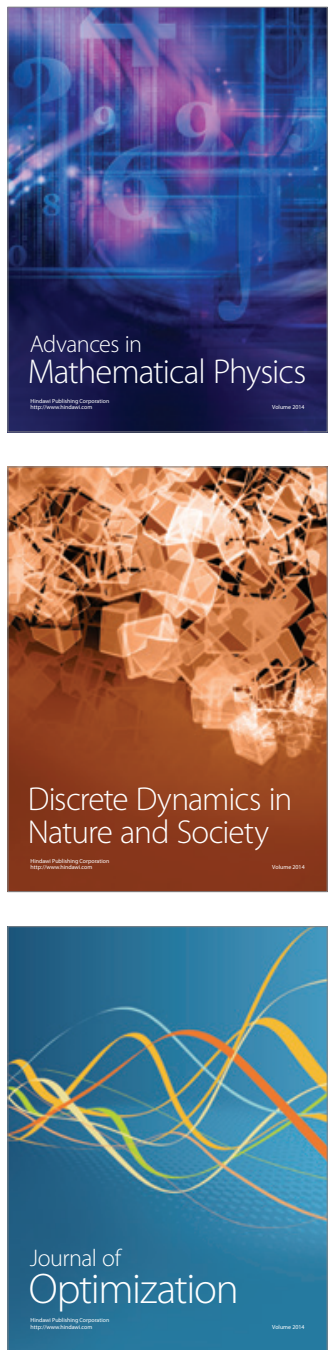